Syntax Fusion : Jurnal Nasional Indonesia

e-ISSN : 2775-4440

Vol. 1, No. 10, Oktober 2021

\title{
PENGARUH MOTIVASI KERJA, STRES KERJA DAN KEPUASAN KERJA GURU MILENIAL TERHADAP TURNOVER
}

\author{
Geraldine Juanita R, Agustian Budi Prasetya \\ Universitas Pelita Harapan, Indonesia \\ Email: juanitageraldine.gj@gmail.com, agustianbprasetya@gmail.com
}

\begin{abstract}
Abstrak
Sebuah institusi pendidikan membutuhkan dana dan waktu untuk proses pergantian guru pada setiap tahunnya. Keadaan tersebut secara tidak langsung dapat mengganggu efektivitas jalannya operasional sekolah. Merujuk pada data yang diperoleh di SD XYZ, menunjukkan bahwa dalam kurun waktu tiga tahun institusi ini mengalami tingkat turnover yang cukup tinggi. Penelitian ini bertujuan untuk menganalisis pengaruh motivasi kerja, tekanan kerja dan kepuasan kerja guru milenial terhadap turnover intention. Penelitian ini dilakukan di SD XYZ Jakarta Timur. Teknik pengumpulan data dalam penelitian ini menggunakan alat survey kuesioner. Teknik pengambilan sampel yang digunakan adalah total sampling, dengan jumlah sampel sebanyak 52 guru. Teknik analisis yang digunakan dalam penelitian ini menggunakan analisis regresi linier berganda. Hasil penelitian menunjukkan bahwa motivasi kerja berpengaruh positif signifikan terhadap turnover intention; tekanan kerja berpengaruh positif signifikan terhadap turnover intention; kepuasan kerja berpengaruh positif signifikan terhadap turnover intention; motivasi kerja, tekanan kerja dan kepuasan kerja secara bersamaan Memiliki dampak yang signifikan terhadap turnover intention.
\end{abstract}

Kata Kunci: Motivasi Kerja, Stress Kerja, Kepuasan Kerja, Turnover Intention.

Diterima: 27-09-2021 Direvisi: 15-10-2021 Disetujui: 18-10-2021

\section{Pendahuluan}

Sebuah institusi pendidikan membutuhkan dana dan waktu untuk proses pergantian guru pada setiap tahunnya, sekolah harus merekrut guru baru serta melatih mereka (Ronfeldt, Loeb dan Wyckoff, 2013). Pergantian guru menciptakan pembelajaran yang tidak stabil bagi suasana kelas, baik pada hubungan antara guru dengan siswa yang secara langsung dapat mempengaruhi pembelajaran siswa dan kedekatan emosional (Melchiorre, 2015). Adapun salah satu masalah yang berpengaruh dengan guru adalah tingkat intensi turnover yang tinggi. Intensi turnover atau keinginan untuk keluar dari suatu institusi pendidikan ke suatu institusi pendidikan lainnya, karena 
beberapa faktor merupakan wujud nyata dari turnover intention guru milenial. Hal ini tentu menjadi masalah serius bagi institusi atau organisasi, khususnya apabila guru yang keluar adalah guru yang mempunyai keahlian, kemampuan, keterampilan dan berpengalaman, serta menduduki posisi penting di dalam sebuah organisasi.

Keadaan tersebut secara tidak langsung dapat mengganggu efektivitas jalannya operasional sekolah. Merujuk pada data yang diperoleh di SD XYZ, menunjukkan bahwa dalam kurun waktu tiga tahun institusi ini mengalami tingkat turnover yang cukup tinggi. Mobley, mengatakan bahwa ada beberapa faktor yang dapat mempengaruhi tinggi rendahnya turnover intention diantaranya yaitu faktor beban pekerjaan seperti stres kerja, lingkungan kerja, dan motivasi yang berdampak positif atau negatif terhadap tingkat kepuasan kerja (Mobley, 2011).

SD XYZ merupakan Sekolah Dasar Swasta yang mengaplikasikan kurikulum nasional dan Cambridge Curriculum. Guru Sekolah Dasar XYZ ini didominasi oleh milenial yang jumlahnya ada sebanyak $90 \%$ dari total jumlah guru yang ada. De Meuse et al (2010), menyatakan bahwa terdapat empat generasi angkatan kerja yang ada di dalam sebuah perusahaan yaitu orang-orang yang lahir antara tahun 1920 sampai dengan tahun 1939 sebagai generasi Boomers, generasi yang lahir antara tahun 1940 sampai dengan tahun 1959 merupakan generasi Xers, generasi yang lahir antara tahun 1960 sampai dengan tahun 1979 adalah generasi Y, sedangkan generasi milenial lahir antara tahun 1980 sampai dengan akhir tahun 2000.

Jumlah guru milenial dengan rentang usia 20 sampai dengan 30 tahun ada sebanyak 29 orang dari total 52 guru yang ada di SD XYZ. Keseluruhan guru yang termasuk dalam kategori milenial tersebut semuanya adalah perempuan dan tidak ada yang laki-laki. Layton, mengatakan bahwa guru perempuan memiliki kecenderungan lebih rajin dalam hal kehadiran dibandingkan dengan guru laki-laki (Layton, 2015).

Sekolah SD XYZ sebagai salah satu institusi pendidikan yang mengharapkan agar tingkat turnover intention rendah, maka pihak manajemen harus dapat memodifikasi tempat kerja yang sesuai dengan kebutuhan guru milenial (Parikh, 2013). Kurangnya perhatian dari manajemen sekolah untuk menyediakan sarana prasarana yang layak bagi guru milenial, secara tidak langsung dapat meningkatkan kecenderungan mereka untuk pindah ke sekolah lainnya. Upaya di atas, menjadi salah satu strategi untuk menurunkan tingkat turnover intention (Webfinance, 2011).

Wilson menyatakan motivasi merupakan hasrat dalam diri seseorang yang menyebabkan orang tersebut melakukan suatu tindakan untuk mencapai tujuannya. Oleh karena itu, motivasi merupakan penggerak yang mengarahkan pada tujuan. Setiap organisasi tentu ingin mencapai tujuan, sehingga peranan manusia yang terlibat didalamnya menjadi sangat penting. Untuk menggerakkan manusia agar sesuai dengan yang dikehendaki oleh organisasi, maka haruslah dipahami motivasi manusia yang bekerja didalam organisasi tersebut (Wilson, 2012).

Stres merupakan isu utama yang menjadi perhatian karena telah menjadi bagian dari kehidupan karyawan dan sulit untuk menghindari stres dari. Stres kerja yang terlalu tinggi dapat mengancam kemampuan seseorang untuk menghadapi kondisi lingkungan 
kerjanya (Budiyono, 2016). Stres kerja perlu mendapatkan perhatian perusahaan karena tidak hanya berpengaruh pada individu, namun juga terhadap perusahaan secara keseluruhan (Waspodo, 2013).

Kepuasan kerja merupakan perasaan positif tentang pekerjaan seseorang yang dihasilkan dari evaluasi karakteristik pekerjaan tersebut. Kepuasan kerja juga merupakan perasaan emosional karyawan terhadap pekerjaannya (Kardam dan Rangnekar, 2012). Meningkatkan kepuasan kerja karyawan adalah kunci suksesnya organisasi, hal tersebut merupakan dasar bagi organisasi untuk melihat seperti apa keinginan karyawan, sehingga secara tidak langsung dapat meningkatkan pengabdian karyawan pada organisasi, (Rizwan, 2014). Berdasarkan uraian pada halaman sebelumnya, maka peneliti tertarik untuk melakukan penelitian ini dalam bentuk penelitian dengan judul, "Pengaruh Motivasi Kerja, Stres Kerja, dan Kepuasan Kerja Guru Milenial Terhadap Turnover Intention di Institusi Pendidikan SD XYZ Jakarta Timur."

\section{Metode Penelitian}

Penelitian ini dilaksanakan di SD XYZ di Jakarta Timur, adapun jumlah kelas sebanyak 6 kelas dengan total siswa sebesar 150 siswa aktif, jumlah guru yang mengajar aktif ada sebanyak 52 guru, dari jumlah tersebut ada sebanyak 29 guru milenial yang berusia dengan rentang usia 20 tahun sampai dengan 30 tahun.

Adapun populasi yang ada dalam penelitian ini adalah seluruh guru yang tercatat mengajar aktif di sekolah SD XYZ Jakarta Timur dengan jumlah guru sebanyak 52 orang. Dikarenakan jumlah populasi guru yang tersedia hanya sebanyak 52 orang, maka teknik sampel yang digunakan dalam penelitian ini adalah menggunakan teknik total sampling yakni teknik pengambilan sampel menggunakan semua populasi sebagai sampelnya.

Adapun teknik pengumpulan data yang dilakukan dalam penelitian ini adalah menggunakan instrumen kuesioner yang berisi pernyataan-pernyataan mengenai variabel-variabel penelitian yang ditanyakan kepada para responden. Adapun skala data yang digunakan adalah dengan menggunakan skala likert yakni skala interval yang terdiri atas interval nilai sangat setuju (5), setuju (4), cukup setuju (3), tidak setuju (2), dan sangat tidak setuju (1).

\section{Hasil dan Pembahasan}

A. Hasil Penelitian

Variabel Turnover Intention

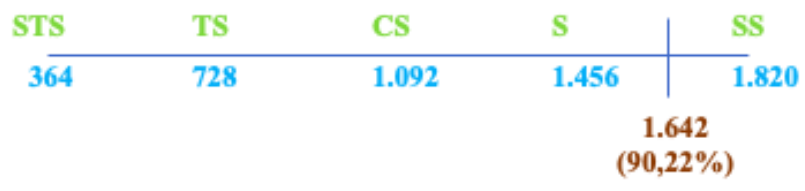

Gambar 4.1. Skala Likert untuk Xariabel. Turnover Intention Sumber. Data primer diolah, (2021). 
Pengaruh Motivasi Kerja, Stres Kerja Dan Kepuasan Kerja Guru Milenial Terhadap Turnover

Sebanyak 90,22\% responden menilai setuju terkait turnover intention guru milenial di sekolah SD XYZ Jakarta Timur adalah tinggi.

Variabel Motivasi Kerja

\begin{tabular}{clll|l} 
STS & TS & CS & S & SS \\
\hline 416 & 832 & 1.248 & 1.664 & 2.080 \\
& & \multicolumn{2}{c}{$\begin{array}{c}1.890 \\
(90,87 \%)\end{array}$}
\end{tabular}

Gambar 4.2. Skala Likert untuk Xariabsh Motixasi Keria Sumber. Data Primer diolah, (2021).

Sebanyak 90,87\% responden menilai setuju terkait motivasi kerja guru milenial di sekolah SD XYZ Jakarta Timur adalah baik.

Variabel Stres Kerja

\begin{tabular}{llll|l} 
STS & TS & CS & S & SS \\
\hline 312 & 624 & 936 & 1.248 & \multicolumn{2}{c}{1.560} \\
& & & \multicolumn{2}{c}{$\begin{array}{c}1.382 \\
(\mathbf{8 8 , 5 9 \% )}\end{array}$}
\end{tabular}

Gambar 4.3. Skala Likert untuk Xariabel Stres Keria

Sumber Data Primer diolah, (2021).

Sebanyak 88,59\% responden menilai setuju terkait stres kerja guru milenial di sekolah SD XYZ Jakarta Timur adalah baik.

Variabel Kepuasan Kerja

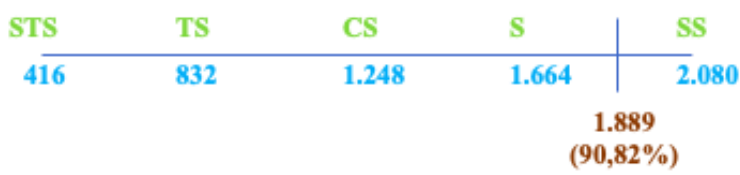

Gambar 4.4. Skala Likert untuk Yariabel Kepuasan Keria Sumber Data Primer diolah, (2021).

Sebanyak 90,22\% responden menilai setuju terkait kepuasan kerja guru milenial di sekolah SD XYZ Jakarta Timur adalah baik.

Pengujian Deskriptif Statistik

\begin{tabular}{|c|c|c|c|c|c|}
\hline \multicolumn{6}{|c|}{ Descriptive Statistics } \\
\hline & $\mathrm{N}$ & Minimum & Maximum & Mean & Std. Deviation \\
\hline Motixasi Keña & 52 & 32.00 & 39.00 & 36.3462 & 1.86700 \\
\hline Stres Keria & 52 & 23.00 & 30.00 & 26.5769 & 1.86133 \\
\hline Kepuasan Keria & 52 & 32.00 & 39.00 & 36.3269 & 2.17581 \\
\hline Turnover Intention & 52 & 27.00 & 35.00 & 31.5769 & 2.08022 \\
\hline Valid N (listwise) & 52 & & & & \\
\hline
\end{tabular}

Sumber. Hasil Running Quput Data SPSS yersi. 26, (2021). 
Geraldine Juanita R, Agustian Budi Prasetya

Masing-masing variabel-variabel independen dan variabel dependen menunjukkan nilai mean yang lebih besar daripada nilai standar deviasi. Hal ini dapat diinterpretasikan bahwa sebaran data pada masing-masing variabel penelitian berada disekitar nilai mean atau nilai rata-ratanya.

\section{Pengujian Keabsahan Data}

Tabel 4.2 Penguiian Xaliditas Data Xariabech Motixasi.Keria

\begin{tabular}{|c|c|c|c|}
\hline $\begin{array}{c}\text { Butir } \\
\text { Pernyataan }\end{array}$ & $\begin{array}{c}\text { Pearson } \\
\text { Correlation }\end{array}$ & $\begin{array}{c}\text { r table } \\
\text { n 52, sig } \boldsymbol{\alpha ~ 5 \%}\end{array}$ & Keputusan \\
\hline B1 & 0,455 & 0,2759 & Valid \\
\hline B2 & 0,343 & 0,2759 & Valid \\
\hline B3 & 0,442 & 0,2759 & Valid \\
\hline B4 & 0,522 & 0,2759 & Valid \\
\hline B5 & 0,304 & 0,2759 & Valid \\
\hline B6 & 0,487 & 0,2759 & Valid \\
\hline B7 & 0,305 & 0,2759 & Valid \\
\hline B8 & 0,368 & 0,2759 & Valid \\
\hline
\end{tabular}

Sumber, Hasil Running Quput, Data SPSS yersi. 26, (2021).

Tahel 4.3 Penguijan Xaliditas, Data Yariabeh Stres Keria

\begin{tabular}{|c|c|c|c|}
\hline $\begin{array}{c}\text { Butir } \\
\text { Pernyataan }\end{array}$ & $\begin{array}{c}\text { Pearson } \\
\text { Correlation }\end{array}$ & $\begin{array}{c}\text { r table } \\
\text { n 52, sig } \boldsymbol{\alpha} \text { 5\% }\end{array}$ & Keputusan \\
\hline B9 & 0,305 & 0,2759 & Valid \\
\hline B10 & 0,368 & 0,2759 & Valid \\
\hline B11 & 0,392 & 0,2759 & Valid \\
\hline B12 & 0,278 & 0,2759 & Valid \\
\hline B13 & 0,622 & 0,2759 & Valid \\
\hline B14 & 0,402 & 0,2759 & Valid \\
\hline
\end{tabular}

Sumber, Hasil Running Quput Data SPSS xersi. 26, (2021).

Tabel 4.4 Penguiian Xaliditas, Data Yariabsh Kenuasan Keria

\begin{tabular}{|c|c|c|c|}
\hline $\begin{array}{c}\text { Butir } \\
\text { Pernyataan }\end{array}$ & $\begin{array}{c}\text { Pearson } \\
\text { Correlation }\end{array}$ & $\begin{array}{c}\text { r table } \\
\text { n 52, sig } \boldsymbol{\alpha} \text { 5\% }\end{array}$ & Keputusan \\
\hline B15 & 0,359 & 0,2759 & Valid \\
\hline B16 & 0,368 & 0,2759 & Valid \\
\hline B17 & 0,415 & 0,2759 & Valid \\
\hline B18 & 0,537 & 0,2759 & Valid \\
\hline B19 & 0,469 & 0,2759 & Valid \\
\hline B20 & 0,464 & 0,2759 & Valid \\
\hline B21 & 0,737 & 0,2759 & Valid \\
\hline B22 & 0,401 & 0,2759 & Valid \\
\hline
\end{tabular}

Sumber: Hasil Running Ouput, Data SPSS yersi, 26, (2021).

Tabel 4.5 Penguiian Xaliditas Data Xariabsh Turnover Intention

\begin{tabular}{|c|c|c|c|}
\hline $\begin{array}{c}\text { Butir } \\
\text { Pernyataan }\end{array}$ & $\begin{array}{c}\text { Pearson } \\
\text { Correlation }\end{array}$ & $\begin{array}{c}\mathbf{r} \text { table } \\
\text { n 52, sig } \boldsymbol{\alpha} \text { 5\% }\end{array}$ & Keputusan \\
\hline B23 & 0,397 & 0,2759 & Valid \\
\hline B24 & 0,715 & 0,2759 & Valid \\
\hline B25 & 0,447 & 0,2759 & Valid \\
\hline B26 & 0,476 & 0,2759 & Valid \\
\hline B27 & 0,583 & 0,2759 & Valid \\
\hline B28 & 0,379 & 0,2759 & Valid \\
\hline B29 & 0,390 & 0,2759 & Valid \\
\hline
\end{tabular}

Sumber, Hasil Running Quput Data SPSS yersi. 26, (2021)

Jurrlul syrllax r uslurl, vU1. 1, INU. IU, UKtUUel $\angle \mathrm{U} \angle 1$ 
Pengaruh Motivasi Kerja, Stres Kerja Dan Kepuasan Kerja Guru Milenial Terhadap Turnover

Nilai pearson correlation pada masing-masing butir pernyataan lebih besar dari nilai $r$ tabel n 52, sig $\alpha 5 \%$ yakni sebesar 0,2759 . Hal ini dapat diinterpretasikan bahwa seluruh butir pernyataan yang ada pada variabel motivasi kerja, stress kerja, kepuasan kerja, dan turnover adalah valid. Artinya indikator-indikator yang ada dapat merefleksikan variabel motivasi kerja dengan baik. Semakin besar nilai cronbach's alpha if item deleted yang diperoleh dibandingkan dengan nilai $r$ tabel $n$ 48, sig $\alpha$ 5\%, maka indikator tersebut akan semakin mampu merefleksikan variabel motivasi kerja dengan sangat baik.

\section{Pengujian Reliabilitas}

Motivasi Kerja

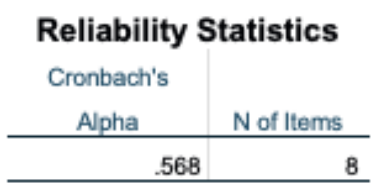

Nilai cronbach's alpha variabel motivasi kerja sebesar 0,568 atau 56,80\% hal ini dapat diinterpretasikan bahwa keseluruhan butir pernyataan yang ada pada variabel motivasi kerja korelasinya cukup kuat.

Stres Kerja

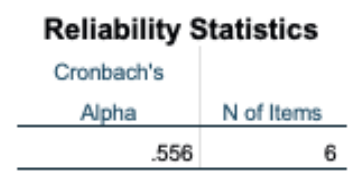

Nilai cronbach's alpha variabel stres kerja sebesar 0,556 atau 55,60\% hal ini dapat diinterpretasikan bahwa keseluruhan butir pernyataan yang ada pada variabel stres kerja korelasinya cukup kuat.

Kepuasan Kerja

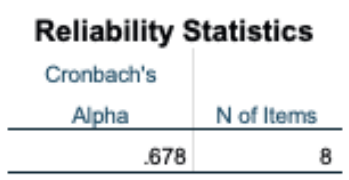

Nilai cronbach's alpha variabel kepuasan kerja sebesar 0,678 atau 67,80\% hal ini dapat diinterpretasikan bahwa keseluruhan butir pernyataan yang ada pada variabel kepuasan kerja korelasinya kuat.

Turnover Intention

\section{Reliability Statistics}

Cronbach's

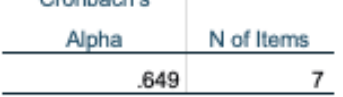


Nilai cronbach's alpha if item deleted yang diperoleh dibandingkan dengan nilai $\mathrm{r}$ tabel n 52, sig $\alpha 5 \%$, maka indikator tersebut akan semakin mampu merefleksikan variabel turnover intention dengan sangat baik. Adapun nilai cronbach's alpha variabel turnover intention sebesar 0,649 atau $64,90 \%$ hal ini dapat diinterpretasikan bahwa keseluruhan butir pernyataan yang ada pada variabel turnover intention korelasinya kuat.

\section{Pengujian Asumsi Klasik}

Terlihat titik-titik menyebar disekitar garis diagonal serta penyebarannya yang mengikuti arah garis diagonal. Maka dapat diinterpretasikan bahwa model regresi pada penelitian ini telah memenuhi pengujian asumsi normalitas residual, sehingga data yang ada dalam penelitian ini layak untuk digunakan pada tahapan analisis selanjutnya.

Multikolinearitas

Variabel motivasi kerja memiliki nilai VIF (variance inflating) sebesar 2,062 $\leq$ 10 dengan nilai tolerance sebesar $0,485 \geq 0,10$. Variabel stres kerja memiliki nilai VIF (variance inflating) sebesar $1,399 \leq 10$ dengan nilai tolerance sebesar $0,715 \geq 0,10$. Sedangkan, variabel kepuasan kerja memiliki nilai VIF (variance inflating) sebesar $2,601 \leq 10$ dengan nilai tolerance sebesar $0,385 \geq 0,10$. Hal ini dapat diinterpretasikan bahwa data pada variabel-variabel independen dalam penelitian ini tidak ditemukan adanya gejala multikolinieritas. Sehingga data ini layak untuk dilakukan pengujian pada tahapan analisis selanjutnya

Heteroskedastisitas

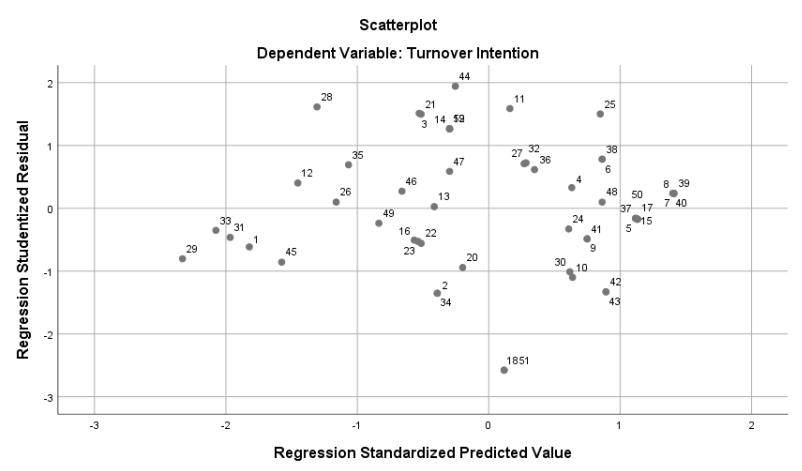

Titik-titik menyebar secara acak, tidak membentuk sebuah pola tertentu yang jelas serta penyebarannya tersebar secara acak, baik diatas maupun di bawah pada angka 0 pada sumbu Y. Hal ini dapat diinterpretasikan bahwa data pada penelitian ini tidak ditemukannya adanya gejala heteroskedastisitas. 
Pengaruh Motivasi Kerja, Stres Kerja Dan Kepuasan Kerja Guru Milenial Terhadap Turnover

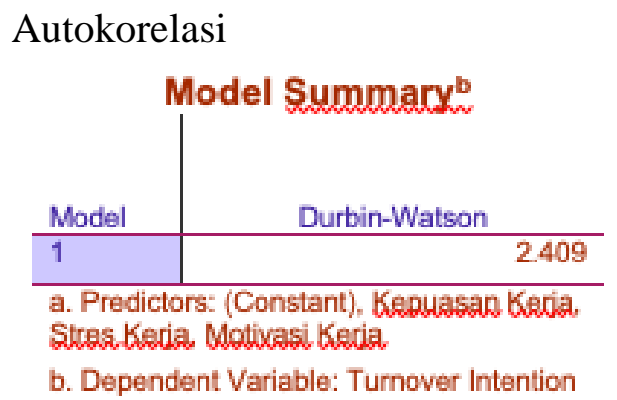

Nilai Durbin Watson (DW) sebesar 2,409. Selanjutnya, nilai ini akan dibandingkan dengan nilai tabel Durbin Watson dengan tingkat signifikansi 5\%, dengan jumlah sampel sebesar 52 sampel, dengan jumlah variabel independen sebanyak 3 atau $\mathrm{K}=3$ yakni 3.53. Maka diperoleh nilai dU sebesar 1,4339. Nilai DW sebesar 2,409 lebih besar dari batas atas (dUA) yakni 1,4339 dan kurang dari (4-dU) yakni $4-1,4339=$ 2,5661. Sehingga dapat diinterpretasikan bahwa data pada penelitian ini tidak ditemukannya adanya gejala autokorelasi.

Pengujian Multi Linear Regression Analysis

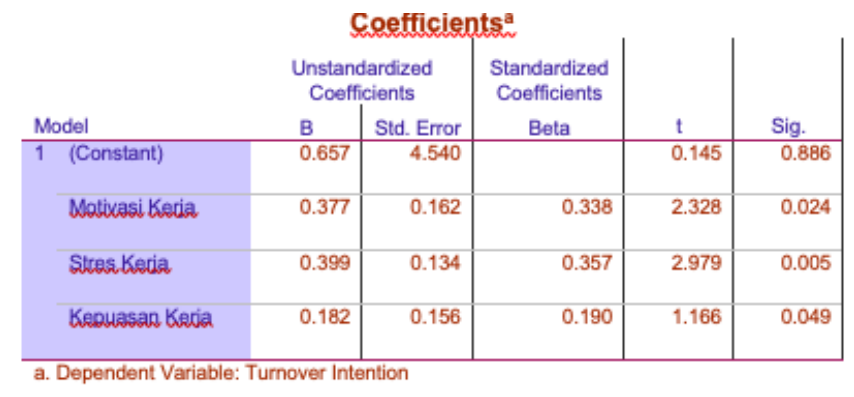

Variabel motivasi kerja memiliki nilai probabilitas signifikansi sebesar 0,024 $\leq$ signifikansi $\alpha$ sebesar 0,05. Maka keputusannya adalah menolak Ho dan menerima Ha. Hal ini dapat diinterpretasikan bahwa variabel motivasi kerja secara parsial memiliki pengaruh yang signifikan terhadap variabel turnover intention. Adapun nilai unstandardized coefficients beta sebesar 0,377 dapat diinterpretasikan bahwa jika variabel motivasi kerja mengalami kenaikan sebesar satu satuan, maka variabel turnover intention juga akan mengalami kenaikan sebesar 0,377 kali, dan hal ini berlaku sebaliknya.

Variabel stres kerja memiliki nilai probabilitas signifikansi sebesar $0,005 \leq$ signifikansi $\alpha$ sebesar 0,05. Maka keputusannya adalah menolak Ho dan menerima Ha. Hal ini dapat diinterpretasikan bahwa variabel stres kerja secara parsial memiliki pengaruh yang signifikan terhadap variabel turnover intention. Adapun nilai unstandardized coefficients beta sebesar 0,399 dapat diinterpretasikan bahwa jika variabel stres kerja mengalami kenaikan sebesar satu satuan, maka variabel turnover intention juga akan mengalami kenaikan sebesar 0,399 kali, dan hal ini berlaku sebaliknya.

Sedangkan, variabel kepuasan kerja memiliki nilai probabilitas signifikansi 
sebesar 0,049 $\leq$ signifikansi $\alpha$ sebesar 0,05. Maka keputusannya adalah menolak Ho dan menerima Ha. Hal ini dapat diinterpretasikan bahwa variabel kepuasan kerja secara parsial memiliki pengaruh yang signifikan terhadap variabel turnover intention. Adapun nilai unstandardized coefficients beta sebesar 0,182 dapat diinterpretasikan bahwa jika variabel kepuasan kerja mengalami kenaikan sebesar satu satuan, maka variabel turnover intention juga akan mengalami kenaikan sebesar 0,182 kali, dan hal ini berlaku sebaliknya.

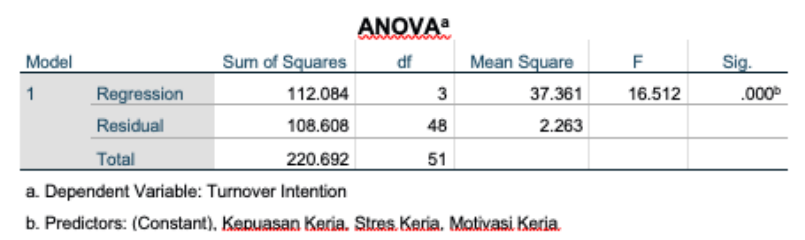

Nilai probabilitas signifikansi $0,000 \leq$ signifikansi $\alpha$ sebesar 0,05 . Maka keputusannya adalah menolak Ho dan menerima Ha. Hal ini dapat diinterpretasikan bahwa variabel motivasi kerja, stres kerja dan kepuasan kerja secara simultan memiliki pengaruh yang signifikan terhadap variabel turnover intention

Pengujian Koefisien Determinasi

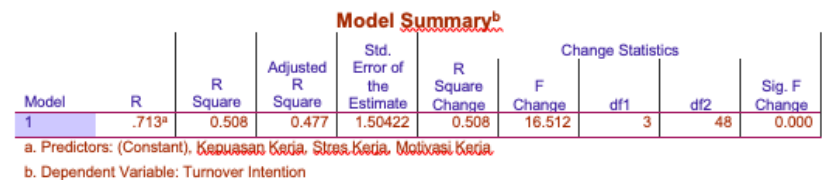

Model regresi diperoleh nilai R2 sebesar 0,508 atau sebesar 50,80\%. Hal ini dapat diinterpretasikan bahwa variabel motivasi kerja, stres kerja dan kepuasan kerja dapat menjelaskan pengaruhnya terhadap variabel turnover intention sebesar 50,80\% dan sisanya sebesar 49,20\% dipengaruhi atau dijelaskan oleh variabel lainnya yang belum terdapat dalam model regresi penelitian ini dan nilai error. Sedangkan, nilai $\mathrm{R}$ sebesar 0,713 atau sebesar 71,30\% dapat diinterpretasikan bahwa tingkat keeratan korelasi antara variabel-variabel independen dan variabel dependen adalah kuat.

\section{B. Pembahasan Penelitian}

\section{Pengaruh Motivasi Kerja Terhadap Turnover Intention}

Berdasarkan hasil pengujian hipotesis pada halaman sebelumnya, maka dapat dijelaskan bahwa variabel motivasi kerja secara parsial memiliki pengaruh yang signifikan terhadap variabel turnover intention. Hal ini mengindikasikan tingginya motivasi kerja guru milenial tidak selalu terkait dengan turunnya kecenderungan turnover intention. Artinya bahwa ketika guru milenial memiliki semangat kerja yang tinggi tetapi lingkungan kerjanya tidak memberikan apresiasi berarti sebagai bentuk aktualisasi diri mereka dalam berkarir, maka mereka secara tidak langsung memiliki keinginan untuk berpindah tempat kerja yang baru yang bisa membuat mereka nyaman karena hasil kerjanya dihargai oleh lingkungan kerjanya. 

Turnover

Sebaliknya ketika guru milenial memiliki motivasi kerja yang rendah maka kecenderungan mereka untuk bertahan pada satu pekerjaan atau dengan kata lain tingkat turnover intention-nya juga rendah. Hal ini dapat diinterpretasikan bahwa meskipun motivasi kerja guru milenial tinggi, belum berarti mereka mau untuk tetap bertahan pada satu tempat pekerjaan, jika tidak ada faktor lain yang mempengaruhinya, seperti lingkungan kerja yang nyaman, hubungan sosialisasi dan komunikasi antar guru yang baik dan sebagainya.

Hasil penelitian ini sesuai dengan hasil penelitian yang dilakukan oleh (Faaroek, 2021), (Wardhana dan Sri, 2020), (Rahmadianti, 2020) dan (Purwati, 2020), yang dalam hasil penelitiannya mengatakan bahwa motivasi kerja memiliki pengaruh yang positif dan signifikan terhadap turnover intention. Motivasi kerja berperan aktif untuk meningkatkan prestasi kerja, produktivitas kerja dengan komitmen pada organisasi.

\section{Pengaruh Stres Kerja Terhadap Turnover Intention}

Berdasarkan hasil pengujian hipotesis pada halaman sebelumnya, maka dapat dijelaskan bahwa variabel stres kerja secara parsial memiliki pengaruh yang signifikan terhadap variabel turnover intention. Hasil penelitian ini sesuai dengan hasil penelitian yang dilakukan oleh (Ardianto, 2021), (Rizky, 2021) dan (Mawadati, 2020) yang dalam hasil penelitiannya menyatakan bahwa stres kerja memiliki pengaruh yang positif dan signifikan terhadap turnover intention.

Stres kerja merupakan suatu gejala atau perasaan yang dapat timbul dalam diri seorang karyawan dan dapat memberikan dampak dalam suatu organisasi yang akan memberikan pengaruh terhadap kepuasan karyawan dan akan mempengaruhi kinerja karyawan (Chaudhry, 2012). Ketika stres kerja meningkat, maka akan menyebabkan timbulnya keinginan untuk keluar yang ada pada diri karyawan, (Chandio, 2013). Stres merupakan isu utama yang menjadi perhatian karena telah menjadi bagian dari kehidupan karyawan dan sulit untuk menghindari stres dari pekerjaan.

Parvaiz di dalam penelitiannya menunjukkan bahwa stres kerja memiliki pengaruh positif dan signifikan terhadap turnover intention (Parvaiz, 2015). Artinya bahwa jika karyawan mengalami stres kerja dan tidak memiliki mekanisme yang cocok untuk mengatasi stres tersebut, maka akan menimbulkan keinginan karyawan untuk keluar. Jadi dapat dikatakan bahwa stres kerja merupakan salah satu variabel yang berpengaruh positif dan signifikan terhadap turnover intention, dimana semakin tinggi tekanan dalam pekerjaan, maka tingkat stres pada karyawan akan meningkat, sehingga terdapat kecenderungan karyawan berpikir untuk meninggalkan organisasi.

\section{Pengaruh Kepuasan Kerja Terhadap Turnover Intention}

Berdasarkan hasil pengujian hipotesis pada halaman sebelumnya, maka dapat dijelaskan bahwa variabel kepuasan kerja secara parsial memiliki pengaruh yang signifikan terhadap variabel turnover intention. Hasil penelitian ini sesuai dengan hasil penelitian yang dilakukan oleh (Pane, 2021), (Rijasawitri, 2020) dan (Margaretta, 2020), yang dalam hasil penelitiannya menyatakan bahwa kepuasan kerja memiliki pengaruh yang positif dan signifikan terhadap turnover intention.

Polii dalam hasil penelitiannya menyatakan bahwa faktor-faktor yang 
mempengaruhi keinginan untuk individu ada dalam kontrol perusahaan terkait dengan kebijakan manajemen yang diambil oleh organisasi antara lain adalah kepuasan kerja dan kelekatan kerja diantaranya keduanya (Polii, 2015). (Susanto dan Gunawan, 2013) mengungkapkan bahwa faktor yang dapat menjadi pemicu terjadinya turnover intention adalah keterkaitan individu didalam organisasi. Sianipar dan Haryanti menjelaskan bahwa ada beberapa tanda-tanda pada karyawan yang akan melakukan turnover diantaranya yaitu jumlah absensi yang meningkat, mulai malas terhadap atasan dan perilaku positif yang berbeda dari biasanya (Sianipar dan Haryanti, 2014).

Berdasarkan hasil pengujian hipotesis pada halaman sebelumnya, maka dapat dijelaskan bahwa variabel motivasi kerja, stres kerja dan kepuasan kerja secara simultan memiliki pengaruh yang signifikan terhadap variabel turnover intention. Hasil penelitian ini sesuai dengan hasil penelitian yang dilakukan oleh Ardianto (2021), Rizky (2021), Rijasawitri (2020), Margaretta (2020) dan Mawadati (2020), yang di dalam penelitiannya mengatakan bahwa motivasi kerja, stres kerja, dan kepuasan kerja secara simultan memiliki pengaruh yang signifikan terhadap turnover intention.

Turnover intention merupakan salah satu bentuk perilaku karyawan yang mengacu pada keputusan karyawan untuk meninggalkan pekerjaannya, (Anshari dan Kuncoro, 2013). Hal ini juga didukung oleh Ardana (2012), yang mengatakan bahwa voluntary turnover intention yang tinggi akan menyebabkan biaya tambahan pada penarikan dan pelatihan serta menurunnya produktivitas sekaligus merusak moral karyawan.

Keinginan berpindah ini harus disikapi sebagai suatu perilaku manusia yang penting dalam kehidupan berorganisasi dari sudut pandang individu maupun sosial, mengingat bahwa tingkat keinginan seorang karyawan berpindah akan mempunyai dampak yang cukup signifikan bagi perusahaan serta individu yang bersangkutan. Dengan tingginya tingkat turnover pada organisasi, maka akan semakin banyak menimbulkan berbagai potensi biaya maupun biaya rekrutmen dan pelatihan kembali.

Di Dalam beberapa kasus tertentu, turnover intention memang diperlukan oleh organisasi terutama terhadap karyawan dengan kinerja yang rendah. Namun demikian, tingkat turnover tersebut harus diupayakan agar tidak terlalu tinggi dan harus ada kontrol, sehingga organisasi masih memiliki kesempatan untuk memperoleh manfaat atas peningkatan tersebut.

Pemberhentian atas keinginan karyawan sendiri dengan mengajukan permohonan untuk berhenti dari organisasi, hendaknya disertai oleh alasan-alasan yang jelas pada waktu yang tepat agar sekolah siap dan dapat mencari penggantinya. Beberapa alasan bagi karyawan yang memiliki keinginan yang berujung pada keputusan untuk meninggalkan tempat kerjanya, umumnya disebabkan oleh beberapa faktor seperti manajemen yang kurang baik, lingkungan perusahaan yang tidak mendukung atau adanya ketidakpuasan akan kinerja maupun hasil yang diperoleh oleh karyawan itu sendiri. 
Pengaruh Motivasi Kerja, Stres Kerja Dan Kepuasan Kerja Guru Milenial Terhadap Turnover

\section{Kesimpulan}

Motivasi kerja secara parsial memiliki pengaruh yang positif dan signifikan terhadap turnover intention. Hal ini didasarkan pada nilai probabilitas signifikansi sebesar 0,024 lebih kecil dari nilai signifikansi alpha sebesar 0,05. Stres kerja secara parsial memiliki pengaruh yang positif dan signifikan terhadap turnover intention. Hal ini didasarkan pada nilai probabilitas signifikansi sebesar 0,005 lebih kecil dari nilai signifikansi alpha sebesar 0,05 .

Kepuasan kerja secara parsial memiliki pengaruh yang positif dan signifikan terhadap turnover intention. Hal ini didasarkan pada nilai probabilitas signifikansi sebesar 0,049 lebih kecil dari nilai signifikansi alpha sebesar 0,05. Motivasi kerja, stres kerja dan kepuasan kerja secara simultan memiliki pengaruh yang signifikan terhadap turnover intention. Hal ini didasarkan pada nilai probabilitas signifikansi sebesar 0,000 lebih kecil dari nilai signifikansi alpha sebesar 0,05. 
Geraldine Juanita R, Agustian Budi Prasetya

\section{BIBLIOGRAFI}

Anggini, F A T., Mochammad A M., Cahyo W S. Pengaruh Gaya Kepemimpinan Transaksional dan Motivasi Kerja Terhadap Kinerja Karyawan Auto 2000 Malang Sutoyo. Jurnal Administrasi Bisnis. 58(1):173-180, 2018. Google Scholar.

Anshari, H., Engkos, A.K. Analisis Pengaruh Organizational Justice dan Work Environment Terhadap Turnover Intention Pada Divisi HRD PT Indosat Tbk. Tesis Dipublikasi. Universitas Bina Nusantara, 2013. Google Scholar.

Ardana, I.K., I Gede Y.K. Peran Komitmen Organisasi dalam Memediasi Pengaruh Stres Kerja Terhadap Turnover Intention. E-Jurnal Manajemen Unud, 7(2), 2018. Google Scholar.

Ardianto, R.E., Muhamad, B. Turnover Intentions: Pengaruh Kepuasan Kerja, Komitmen Organisasional dan Stres Kerja. Jurnal Ekonomi Manajemen dan Bisnis EKOMABIS. 2(1): 89-98, 2021. Google Scholar.

Aryanto, D., Hardi H.P. Pengaruh Stres Kerja dan Emotional Intelligence Terhadap Turnover Intention, E-Jurnal Manajemen, 298(1), 2019. Google Scholar.

Auda, R. M. Pengaruh Kecerdasan Emosional Terhadap Komitmen Organisasi Melalui Kepuasan Kerja Sebagai Variabel Mediasi Pada Bank DKI Kantor Cabang Surabaya. Jurnal Bisnis dan Manajemen BISMA. 8(2): 156-176, 2016. Google Scholar.

Bangun, W. Manajemen Sumber Daya Manusia. Jakarta: PT Gelora Aksara Pratama, 2012. Google Scholar.

Carolina, YP. Pengaruh Iklim Etika Terhadap Komitmen Organisasi dan Turnover Intention (Studi Kasus: PT Trac Cikarang), 2012. Google Scholar.

Charles, B P., Putu N G. The Influence of Work Motivation, Organization Culture and Career Development on Employee Performance in PT. Titis Sampurna Inspection. Saudi Journal of Business and Management Studies. 629-640, 2018. Google Scholar.

Chaudhry, A.Q. The Relationship Between Occupational Stress and Job Satisfaction: The Case of Pakistan Universities. International Education Studies, 5(3): 212221, 2012. Google Scholar.

Chukwuma., Obiefuna. Teori dan Aplikasinya. Jakarta: Bina Aksara, 2014. Google Scholar.

Davis, K., Newstrom, W. Perilaku dalam Organisasi (Jilid I) Edisi Ketujuh. Jakarta: Erlangga, 1013. Google Scholar.

Dharma, A. Manajemen Supervisi (Cetakan Revisi Kelima). Jakarta: Raja Grafindo, 
Pengaruh Motivasi Kerja, Stres Kerja Dan Kepuasan Kerja Guru Milenial Terhadap Turnover

2014. Google Scholar.

Faaroek, A. Pengaruh Budaya Organisasi Terhadap Turnover Intention Melalui Motivasi Pada Karyawan Generasi Milenial. Jurnal Forum Ilmiah Universitas Esa Unggul. 18(1): 1-15, 2021. Google Scholar.

Kurniawan, A. W. Pengaruh Kepemimpinan dan Pengembangan Sumber Daya Manusia Terhadap Kepuasan Kerja, Motivasi Kerja, dan Kinerja Karyawan Bank Sulawesi Barat. Jurnal Ekonomi dan Keuangan. 16(4), 2012. Google Scholar.

Manurung, M.T., Ratnawati, I. Analisis Pengaruh Stres Kerja dan Kepuasan Kerja Terhadap Turnover Intention Karyawan: Studi Pada STIKES Widya Husada Semarang. Journal of Management, 1(2):145-157, 2012. Google Scholar.

Mawadati, D., Asep R.P.S. Pengaruh Kepuasan Kerja dan Stres Kerja Terhadap Turnover Intention Karyawan, Jurnal Forum Ekonomi, 22(1): 18-26, 2020. Google Scholar.

Pane, M., Poltak P.S., Nufrizal. Pengaruh Komitmen Organisasi, Lingkungan Kerja dan Kepuasan Kerja Terhadap Intensi Turnover Pegawai Pada Dinas Perikanan Kota Tanjungbalai. Manajemen Bisnis Jurnal Magister Manajemen, 3(1): 78-87, 2021 Google Scholar.

Purwati, A.A., Cindy, A.S., Zulfadli, H. Pengaruh Kompensasi, Motivasi Kerja dan Beban Kerja Terhadap Turnover Intention Karyawan. Jurnal Ilmiah Manajemen (Procuratio), 8(3): 370-381, 2020. Google Scholar.

Putra, B.R. Pengaruh Job Stressor Terhadap Turnover Intention dengan Kepuasan Kerja Sebagai Variabel Pemediasi. Jurnal Studi Manajemen Indonesia, 2012. Google Scholar.

Putra, M.S., Ni Kadek W.S.N. Pengaruh Stres Kerja, Kepuasan Kerja dan Komitmen Organisasi Terhadap Turnover Intention Pada Karyawan, E-Jurnal Manajemen, 8(10), 2019. Google Scholar.

Putri, R., Suana IW. Pengaruh Job Embeddedness, Kepuasan Kerja dan Komitmen Organisasional Terhadap Turnover Intention Karyawan. E-Jurnal Riset Ekonomi, Manajemen, Bisnis dan Akuntansi, 2016. Google Scholar.

Rahmadianti, Y., Syukri L., Rima S. Analisis Pengaruh Kepemimpinan dan Motivasi Terhadap Turnover Intention Karyawan dengan Komitmen Organisasi Sebagai Variabel Mediasi Rumah Sakit Islam Siti Rahmah. Jurnal Kesehatan Andalas, 9(1): 19-25, 2020. Google Scholar.

Waspodo, A.A., Handayani, N.C., Paramita, W. Pengaruh Kepuasan Kerja dan Stres Kerja Terhadap Turnover Intention Pada Karyawan PT Unitex di Bogor. Jurnal Riset Manajemen Sains Indonesia, 4(1): 97-115, 2013. Google Scholar. 